\title{
Being Intercultural Through Texts: The Student as Text Ethnographer
}

\section{Introduction}

In the previous chapter I looked at views of the nature of language and the nature of culture, particularly as applied to the context of language education. In this chapter I focus on the intercultural aspect of language pedagogy and develop the idea of being intercultural through text. I argued in chapter 2 that the relationship between language and culture is very close on a generic level, but not at a differential level, i.e. there is not a direct and straightforward link between a particular language and a particular culture. At the generic level, language and culture come together through discourses. I use discourses in the way that Foucault uses these; discourses as discursive formations giving rise to certain routinised ways of talking and thinking about specific topics or areas of social life. I argued for an approach to language teaching which is akin to cultural studies, taking account of the notion that language is to a large extent a social construct which is influenced by its context of use. The complexity of the interrelationship between language and its context of use is reflected in discourses, voices and genres; language as 'styles for certain spheres of human communication' (Bakhtin, 1986: 64).

For that reason, I want to extend the notion of context as used in language teaching beyond that of merely situational and immediate concerns, to include a 'context of culture' (Kramsch, 1993), as the area where meaning is constructed. Context is then not just formed by the situation in which the communicative event takes place, but also by what the broader views, ideas, and taken-for-granted assumptions and meanings are in particular contexts of use. 
Cultural studies as a discipline itself can be approached from at least two different angles, Turner (1992) says: a text-based or a context-based approach. With the former he refers to the study of texts from literature, film or popular media. With the latter he refers to Area Studies: courses which cover historical, social and political aspects. Arguably, the same applies to language teaching. I will refer to Kramsch's 1993 book, Context and Culture in Language Teaching and to Byram's notion of Intercultural Communicative Competence as the two dominant examples of respectively a text-based and a context-based approach, at the time when I started this study. Both Byram and Kramsch have slightly rearticulated their positions, but many of their basic tenets are still relevant, and indeed often referred to in the pedagogic literature.

Both approaches have taken language teaching out of the mere functional concerns of communicative language teaching and have advanced language and culture pedagogy. Both challenge the myth of 'the native speaker', and both use the model of the Intercultural Speaker. I build on both Kramsch's and Byram's approaches for my own pedagogy. However, I believe we need to further problematise the nature of intercultural communication, and acknowledge its complexity, particularly in multicultural and global societies, without denying the existence of cultural patterns.

To do so I will look at Blommaert who, although not a language pedagogue, puts forward a view of intercultural communication which can be usefully applied to the debates about language and culture pedagogy. I make use of Blommaert's insights and relate these to various emerging views in the last few years of a new conceptualisation of intercultural communication in language teaching. But, whilst intercultural communication and the inclusion of culture in the language curriculum is a much-debated issue at a theoretical level ( $\mathrm{cf}$ Risager, 2007; Phipps and Guilherme, 2004; Starkey, 1999; Sercu, 2005; Fenoulhet and Ros i Solé, 2010, to name but a few) in practice, this is still haphazard in many course books, certainly in Dutch, and is even ignored in influential language exams.

My challenge then is to find a model of language teaching as part of a general language course that contributes to the development of the learner as a critical intercultural language user. In this chapter I build on the concepts discussed in the previous chapters which underpin such a pedagogy, and in chapters 5 and 6 I look at how students engaged with this pedagogy.

\section{Intercultural Communication in Language Teaching}

\section{Ideas and Practices}

The notion of a pedagogy of intercultural communication as part of language and culture teaching was not formally theorised until the 1990s. Michael Byram in Britain (c.f. Teaching and Assessing Intercultural Communicative Competence, 
1997) and Claire Kramsch in the US (Context and Culture in Language Teaching 1993 ) have been the main reference points in this area. In the last few years particularly, the idea of intercultural communication as the area where language and culture meet in the classroom, has gained momentum and different strands and views are being developed. My intention here is not to give an overview of these developments; Risager (2007) offers a comprehensive overview and discussion of this field. Here I will set out to what extent Kramsch and Byram, as well as others, have influenced my perspective on language and culture teaching and to what extent I deviate from them.

As I said earlier, I suggest that a cultural studies-oriented language and culture pedagogy can be approached from two different practical starting points: a text-based or a context-based approach. Kramsch uses the former, Byram the latter.

Both approaches rely on text as well as context in their pedagogy, but the differences lie in the main focus of the pedagogical tool; a text-based approach aims to develop an understanding of culture and language through analyzing texts, whereas a context-based approach focuses on the cultural situations in which language is used, as well as on a body of knowledge that is taught, discussed or 'discovered'. In a text-based approach the role of cultural knowledge is less fore grounded; knowledge is conceived of as the contextual knowledge needed in order to interpret the text. But knowledge is then also conceived of as meta-knowledge; knowledge of the interpretation process itself and the concepts needed to talk about the texts. Kramsch uses texts as the starting point of her pedagogy. Byram on the other hand, represents a socially oriented, especially an ethnographic, approach through making cultural knowledge an important part of his pedagogy, following on from the idea of Area Studies which I discussed in the previous chapter.

\section{A Text-based Bakhtinian Approach: Kramsch}

It may seem paradoxical to locate Kramsch in a text-based rather than a contextbased pedagogy when her great contribution to language and culture pedagogy is her conceptualisation of context as a complex structure. But here I refer to the pedagogical tools which Kramsch uses, which involve looking at texts, in her case, specifically literary texts. This is not to say that she does not use other classroom activities: on the contrary, her follow up activities after reading a text could, for instance, include a role play trying to emulate the 'voices' in a text.

Kramsch's pedagogy has roots in the European liberal humanist philosophy of education, with a text-based analytical approach and concerns for developing the intellectual and critical ability of students. In contrast, Byram aligns himself more with instrumental and pragmatic goals of language and culture learning, as we will see later, although he takes a much less reductive approach than the strong instrumentalist paradigm which I criticised in chapter one. 
Working in the American context, Kramsch criticises the instrumentallyoriented action pedagogy, rather than a reflection-oriented one. Its sole concern to get students to talk and write as well and as fluently as possible has, she argues, trivialised language teaching. In such a syllabus the teaching of culture has become a controversial issue, as the argument is that depth and breadth of thought belong to other subjects (1993: 4).

This instrumental approach is also very dominant in teaching Dutch as a foreign language, as evidenced by course books and the examination which is taken worldwide by adult learners of Dutch as a foreign language, Certificaat Nederlands als Vreemde Taal (CNaVT). As I set out in chapter 1, the instrumental approach is also becoming more dominant in language teaching at universities in Britain, particularly since language teaching in the context of language degrees is increasingly taught through special provision in places such as Language Centres. This means language classes are separated from the so-called 'content' classes which are perceived to be intellectually superior.

I align myself with Kramsch's educational aims. As I argued in chapter 1, although the main aim of the general language class is to be able to use the foreign language, there is a developmental and intellectual aspect to language learning, over and above learning a skill.

Kramsch's pedagogy of language learning provides the critical and intellectual demands in terms of students needing to reflect on the interrelationship between text and context. Her pedagogy focuses on the interaction between linguistics and social structures: teachers should not teach either form or meaning but the interaction between the two, she emphasises. Her approach to language and culture pedagogy was new in 1993, and still holds valuable insights. Kramsch's contribution, I feel, is that she provides a more fully conceptualised notion of context than that previously offered in the Threshold levels which saw context only in relation to set phrases tied to certain set situations which occur in typical everyday pragmatic exchanges of shopping, getting a coffee and so forth. But also, crucially, she considers a range of theoretical models from linguistics, ethnography of communication, and language philosophy to provide a view of context, not as a natural given, but as a social construct.

Context, she suggests, consists of linguistic, situational, cultural, interactional and intertextual dimensions. In describing context as being 'shaped by people in dialogue with one another in a variety of roles and statuses' (p. 67), she marries Hymes's model of communicative competence, Halliday's notions of context (1989), and Bakhtin's notion of dialogue. Context is then created by situations, including the classroom situation itself, previous 'cultural' knowledge, as well as the ongoing dialogue or interaction between people and their socio-cultural environment. Crucially, she adds the dimension of intertextual context; the relation a text has to other texts, assumptions, and expectations. The notion of intertext comprises not just the other texts, assumptions and expectations a 'text' may refer to, but also the assumptions, 
expectations and previous experiences of texts that readers themselves are imbued with.

Kramsch suggests that in an intercultural communicative event, the engagement between the language user's own cultural context and that of the cultural context of the interlocutor (or the text) creates a new or 'third culture' where the perceptions and knowledges of the interlocutors about their own and the 'other's' culture intermingle. This also happens, she suggests, in a classroom context, particularly in a multicultural one, where complex relationships take place between the students, the teacher, the foreign language, the 'target' culture and the culture of the learners themselves (ibid. p. 13). In this 'third culture' or 'third place' students can express their own meanings and discover their own identities in a foreign language without being bound by either their own, or the target speech community's identity (ibid. p. 256). It is a place where hybridity and plurality flourish. For my initial pedagogy, I interpreted the metaphor of 'third place' as a space for learning and dialoguing in the classroom, where a 'dialogue' can take place between students themselves, between students and the teacher and between students and the text under discussion. Reading the text becomes a 'dialogue' with the text, as the text will be rewritten, reinterpreted and re-accentuated several times during the classroom discussions. However, the notion of hybridity, which is encompassed in the idea of 'the third place', is one which is also problematic. Whilst the notion of the third space allows the classroom to be perceived as a place where cultures intermingle, meet and clash, and where students can become 'border crossers', it also assumes students identify strongly with their 'native culture', and that their intercultural encounters will be with people who identify strongly with 'the target culture'. Kramsch has now distanced herself from the idea of the 'third place', as being too static and not capturing the relations and operations between multilingual learners (2009: 200). For my own pedagogy, I interpreted the dialogic space in the classroom as 'being intercultural', which means, as Phipps and Gonzalez say, it is 'beyond the captivities of culture' (2004: 168), where students engage with language and culture in a process which Phipps and Gonzalez call 'languaging.

For the purpose of this chapter I will remain with Kramsch's 1993 book, even though it does not encompass the idea of 'being intercultural' as the messy, indeterminate and fluid struggles with which her later work is concerned. Her pedagogy described in Context and Culture in Language Teaching, influenced my own approach, particularly since it is largely based on the use of texts. Her approach, partly rooted in the liberal paradigm, is geared to giving access to a range of speech communities, which then opens up areas for reflection and discussion and introduces the idea of multivoicedness in texts (1993: 27).

Kramsch's contribution to language and culture pedagogy, as I said earlier, has been inspiring because of the conceptualisation of context as a complex 
social construct. Moreover, she distances herself from a strong national paradigm in language teaching. She criticises the link made in many language textbooks by which any speaker of the language is automatically representative of any national (e.g. German) speech community. It is rarely acknowledged in language teaching, she says, that even if learners share a common native language, 'they partake of a multiplicity of 'cultures' (1993: 93).

Risager criticises Kramsch for not systematically analysing the relationship between linguistic practice (as cultural practice) and cultural context. Risager's criticism focuses particularly on Kramsch's radical social-constructivist position and the fact that Kramsch does not sufficiently distinguish between the relationship of language and culture at a generic or at a differential level (2007: 108). Risager and I (see my argument in chapter 2) agree with Kramsch that language and culture relate at a generic level; the cultural meanings and connotations of language utterances which are reflected and refracted by participants in contexts of use. But, Risager suggests, Kramsch is close to suggesting that language as text, and cultural context are identical. Risager suggests instead to make a distinction between the 'aspects of the context that are directly created via the linguistic interaction, e.g. the immediate social relations, and the aspects of the context that exist in advance as objective facts and that constitute the historically specific setting' (2007: 109). This reflects Risager's particular point of view regarding the relationship between language and culture as well as the inclusion of cultural knowledge in the curriculum.

My own criticism with regard to Kramsch's 1993 book is slightly different from Risager's. For Kramsch, cultural knowledge (which Risager refers to as 'objective facts that constitute the historically specific setting') relates to both the shared cultural knowledge in the context of production as well as in the context of reception. Kramsch does not see it as necessary that students need a coherent body of knowledge of the cultural context, i.e. the national context. Instead students will need to have the cultural knowledge needed to interpret the text at hand and to be able to relate the text to both the context of production as well as the context of reception in the target speech communities. I agree with Kramsch on this. I also like the fact she uses text in her pedagogy, as her concern, like my own, is with meaning making. However, the texts that Kramsch uses in the classroom tend to be from the literary genre only, whereas I provide another angle by including mass media texts which are rich in discursive constructions. The latter is not one of Kramsch's concerns. Her aim is not to critique power and knowledge constructions in text, and her focus tends to be at the differential level, with particular languages and particularities of culture, rather than with 'discursive formations'. Whilst I feel that the Bakhtinian textbased approach of Kramsch goes a long way in helping students to understand the complexity of communication and the complexity of context, it does not address the discourses and power as they are used in everyday language events. 


\section{A Social and Context-based Approach: Intercultural Communicative Competence}

It is precisely the text-based approach that has attracted criticisms from other scholars in the field of language and culture teaching. Byram particularly takes issue with the text-based approach and its focus on literary texts. He positions himself against the literary tradition in language teaching, because it does not deal with the real every day world in the target language countries. This view of culture, as I discussed in chapter 2, is the anthropological one (cf. Byram, 1989). In this context-based approach the 'real world' is the starting point for the pedagogy, whether in terms of factual knowledge, or communicative events. Whilst Kramsch and Byram agree on the need for reflection on the 'other'; as well as the learner's 'own' culture, for Kramsch this reflection takes place through thinking and talking about texts, particularly in relation to how learners interpret the contexts of production and reception. For Byram this reflection takes place through focusing on and comparing information about 'the' culture, especially relating to everyday life. For Byram then, cultural knowledge is a very important part of the syllabus, whereas cultural knowledge for Kramsch is incidental; it is part and parcel of discussing the context of production. As mentioned above, for Kramsch it is not desirable that students learn a body of coherent cultural knowledge related to 'the' foreign or 'target' culture, whilst Byram feels there is a certain body of knowledge that students learning a foreign language need to possess.

Byram's work in theorising language and culture pedagogy became enormously influential in Europe as a whole. In fact, culture pedagogy, as Risager (2007: 92) points out, did not get under way until Byram's work in the 1980s. He formulated the notion of Intercultural Communicative Competence (ICC for short) as a model for language teaching and assessment of language learners which focuses on acquiring linguistic as well as socio-cultural knowledge and discourse competence (1997: 73). Byram builds on Van Ek's notion of communicative competence which is focused on language rather than culture. To understand people of other national groups, Byram notes, we cannot only depend on 'communicative competence'; learners also 'need to acquire the ability to comprehend cultural differences and cultural relativity' (1992: 165). Byram sees language and culture learning as clearly consisting of a language and a culture element, but these generally remain, unlike with Kramsch, separate.

One of the important new aspects of Intercultural Communicative Competence is that learners not only need to learn about the foreign culture, but that they also need to relate this to their own cultural experiences. Byram based the idea of Intercultural Communicative Competence on the concept of the Intercultural Speaker which he developed with Zarate as part of the work they undertook for the Council of Europe with the project Language Learning for European Citizenship (1997). The aim of language teaching is not for language 
learners to try and emulate 'the' native speaker, but to become 'intercultural speakers'. The notion of the Intercultural Speaker has become a widely accepted goal of language teaching and has replaced the previously used target aim of 'near-native competence' at most (except for the most traditional) Higher Education Institutions. The intercultural speaker is 'someone who has an ability to interact with 'others', to accept other perspectives and perceptions of the world, to mediate between different perspectives, to be conscious of their evaluations of difference.' (Byram et. al. 2001: 5).

Intercultural communicative competence (ICC) is to a large extent formulated as a set of competences. These are a range of skills and knowledges that can be taught as well as assessed, which Byram called the 5 savoirs. The savoirs present a complex picture of the skills needed to be a competent intercultural speaker, including (socio-)linguistic skills, cultural knowledge and a focus on intercultural attitudes, and being prepared to relativise one's own values, beliefs and behaviour.

Promisingly, the savoirs also include what Byram calls, 'critical cultural awareness' (savoir sengager). With this Byram means that learners can turn their attention to their own beliefs and belongings, and in doing so become aware of their own (often unconscious) cultural assumptions. He also introduces a political and critical element to language teaching. The learners, Byram (1997: 20) says 'can also be encouraged to identify the ways in which particular cultural practices and beliefs maintain the social positions and power of particular groups. The analysis can become critical'.

I agree with Byram's emphasis on the context of everyday culture and reflecting upon one's own preconceptions in cultural exchanges. This has developed into the inclusion of self-reflection activities and ethnography in language teaching (cf. Byram and Fleming, 1998) and preparing students for residencies abroad, such as the 'The Intercultural Project' at Lancaster University (http:// www.lancs.ac.uk/users/interculture/subproj4.htm) and the Ealing Ethnography Research Project developed at Thames Valley University (Roberts et.al. 2001). It is particularly the development of critical awareness and ethnography, which I feel is very beneficial for language learners, because the methodology of ethnography helps learners to become intercultural.

Byram's notion of Intercultural Communicative Competence then is very helpful in addressing learners' engagement with the complexities of everyday cultural contexts. The model provides a clear method for developing a range of competences. However, this approach is not sufficient on its own to fully address areas of criticality and super-complexity. Its emphasis is on encounters between cultures by reflecting on comparisons between 'the target culture' and the learners' own, and which, despite Byram's emphasis on differences within cultures, can easily lead to assuming relatively fixed notions of these 'cultures'. And whilst the Intercultural Speaker has an open attitude towards the cultural other, she, as Ros i Solé (2013) points out, does not move in and out of, and in between different cultures. Nevertheless, it is particularly Byram's fifth savoir, 
'critical cultural awareness', which provides most insights for culture pedagogy based on views of culture as complex. Guilherme developed the idea of critical cultural awareness to focus on just that.

\section{Guilherme's Citizenship Agenda: The Critical Intercultural Speaker}

Guilherme developed a pedagogical and philosophical framework as a possible formulation of a critical approach to intercultural language learning which is a more complex and theoretical extension of Byram's notion of critical cultural awareness. She locates this pedagogy, like Starkey (cf. 1999, 2010) within the area of citizenship education. Being critical in this approach means 'questioning dominant cultural patterns and seeking the reasons which lead to these patterns being blindly accepted and unquestioned' (2002: 19). Guilherme borrows from Giroux's (1992) notion of 'border pedagogy' in which critical reflection is an important element. Referring to Barnett (1997), who saw reflection as 'meta-critique', she explains that in order to question dominant patterns one has to take a critical perspective towards one's own knowledge and social context, as well as being critical in trying to inhabit someone else's cognitive perspective. Critical reflection is then a vital element in developing cultural awareness as, when reflecting on cultural differences, it will help to make explicit how one justifies one's own beliefs and actions, as well as how these beliefs and actions might be perceived by the other, Guilherme states (2002: 40). She continues: 'From this perspective, reflection-in-action allows for the coming into consciousness of factors that interact in a cross-cultural event such as the unconscious concepts and rules or routine responses that are taken for granted by each side as well as the emotional impetus that drives the intercultural encounter (ibid). In her critical approach to intercultural language learning, Guilherme attempts to respond to the contemporary complex realities of border crossings, of multiculturalism and hybridity. Her 'border pedagogy' rejects a Eurocentric approach towards any culture and favours the inclusion of nonEuropean cultures in curriculum content. It perceives the cultural subject as multifaceted, ever-changing, and in relation to a complex, also evolving society (Guilherme, 2002: 43). Border pedagogy then does not only involve the acknowledgement of facts, that is, the input of geographical, historical, social or political information. 'It should focus on the complexity of hidden meanings, of underlying values, and how these articulate with the micro- and macrocontexts they integrate (ibid:45).' Guilherme takes a transnational perspective in formulating the notion of the 'critical intercultural speaker' (her emphasis). The critical intercultural speaker, she states (ibid: 126, 127) has to problematise the concepts of nationality and ethnicity, both in terms of their origin and their present developments. She must be aware that the development of identities involves a 'constant negotiation between remembering and forgetting, idiosyncracies and common interests'. Guilherme looks towards Giroux again 
who states that the pedagogical goal is not to have students exercise rigorous analytical skills in order to arrive at the right answer but to have a better understanding of what the codes are that organise different meanings and interests in particular configurations of knowledge and power (Guilherme quoting Giroux, 2002: 46). By reflecting on these configurations, students studying a foreign culture should be able to translate them into their own contexts. 'The meanings and interests of the Other will echo their own thoughts and feelings and, by becoming critically aware of them, students will identify and clarify their own struggles, points of view, predisposition which are likely to help them make more enlightened choices' (ibid).

Guilherme's framework offers a multi-perspective approach as she borrows from modernist theories, such as Critical Theory and Critical Pedagogy, and from postmodernist approaches. In this, there are similarities with my own pedagogy that I describe in chapter 4 , as being located in different paradigms of modernist and postmodernist critique, although as I have mentioned before, there was an incommensurable element to my own multi-perspective approach. Risager (2007: 151) critiques Guilherme precisely for this. On the one hand she seems to refer to a language-nation derived concept of culture, and on the other hand, she formulates a language independent conception based on 'border-crossing, 'hybridity' and 'diversity. My own feeling is that Guilherme's thoroughly theorised model has much to offer for considering practical pedagogies for the critical intercultural language user. Her focus is on citizenship, rather than on actual language and texts, and thus functions more as a theoretical consideration than a practical example. However, Guilherme's theoretical considerations in relation to problematising the national view and the idea of stable identities resonates with my own pedagogy.

I now want to make a slight detour from the discussion about how language and culture pedagogy can do justice to the complexity of this relationship and develop learners as critical intercultural speakers, and look at how intercultural communication has been conceptualised in the discipline of intercultural communication itself. I shall then draw on this for an application to language pedagogy.

\section{Three Views of the Study of Intercultural Communication}

The study of intercultural communication (ICC) as a disciplinary study in its own right does not seem to have had a strong influence on language teaching. As I have set out in chapter 2, other theories have been brought to bear upon language teaching. However, I believe that it is worthwhile to take a brief look at different views in use in the discipline of 'intercultural communication', because this disciplinary area is focused on actual communication - 'what happens when people engage in an exchange of meaningful semiotic symbols' (Blommaert, 1998: 1). There are various historical overviews of this area of study, 
but I will use a talk given by Blommaert (1998) which charts three views of intercultural communication with different ideological underpinnings. Whilst Blommaert charts these views, by his own admission, in a sketchy manner, it is relevant for my purpose, precisely because he takes an approach which concentrates on how 'culture' affects, or is seen to affect, speech styles. And, whilst my research is not about speech styles as such, it is about language and culture connecting in everyday speech in everyday communicative events.

\section{Culture and Difference}

The first model which Blommaert highlights is a strongly essentialist one. $\mathrm{He}$ points to a large body of work which shares the theoretical premise that modern nations have dominant national character traits which can be revealed by measurable data. Cultures in this model are described as essential values and practices and are therefore seen in terms of their difference from one another. This model is particularly dominant in the area of ICC studies (intercultural communication) for business purposes (cf. Pinto, 1990; Hofstede, 1994). Culture in this model is seen only in terms of behaviour or as a set of fixed values and beliefs. Culture is then viewed as a problem that can lead to misunderstandings: culture as a problem to be overcome. As Hofstede said on his website in 2010, 'cultural differences are a nuisance at best and often a disaster', although this statement has now disappeared from the website in question.

It is undoubtedly the case that in order to make sense of the multitude of ideas, impressions, and information that we experience in our everyday life, humans need to order these impressions into categories. To be fair to the body of work produced in the business related field, this work is not produced in the context of education with its developmental and intellectual aims that I argued for in chapter 1, but in the context of training with its instrumental aims. The aim is not to understand the complexities of the world, or to be critical but to understand behaviour which would otherwise be 'puzzling or unacceptable' (Verluyten, 2000: 340 ) or lead to 'misunderstanding, miscommunication and mismanagement, of which damage to business and personal interest can be the result' (Pinto quoted by Blommaert, (1998: 2)). And with the increasing emphasis on instrumentalism in language teaching in Higher Education, it is prudent to be alert to these argumentations which are borne out of commercial self-interest. The problem with the difference view of ICC is precisely the simplification of a complex social and cultural world to a coherent, manageable set of fixed ideas. As I argued in my previous chapter, language teaching should help students to recognise the complexity of the world and not focus on ideas that lead to stereotyping.

Blommaert strongly criticises the essentialised 'difference' model, not only because this model posits a simplified notion of culture, but more problematically still, because this model draws a direct and simplified link between 'culture' 
and communication. Kumaravadivelu (2007: 213) quotes Hall, who developed the first courses in 'intercultural communication' for American diplomats, as having declared unequivocally that 'culture is communication and communication is culture' (Hall, 1959: 186). The model assumes that the way that people communicate is related to 'their' culture, frequently interpreted as a national culture, rather than to a range of other social, political or individual factors. As referred to in chapter 2, seeing a national culture in terms of shared values and norms begs the question: are these values shared by everyone all the time? It also assumes that nationality and identity are natural givens, rather than constructions which are perpetuated through everyday conceptualizations of the nation, such as in weather reports, what Billig (1995) called 'banal nationalism'. Nationality does not dictate a particular communicative style. At the very most, people's nationality or ethnic identity may suggest tendencies; the 'possibility of ethnic or cultural marking in communicative behaviour [...], but it in no way imposes ethnic or cultural characteristics onto the communicative behaviour a priori.' (my emphasis). Moreover, presenting intercultural communication as dealing with the 'other' who has his/her own set of different values and behavioral styles that follow on from that, leads to a 'massive overestimation of the degree of and the nature of difference in speech styles' (Blommaert, 1998: 5).

Whilst he criticises the essentialised model of difference as represented by intercultural consultants such as Pinto and Hofstede and numerous others, Blommaert also criticizes the cultural relativist idea of what he calls horizontal stratification. Differences in terms of differentials such as age, nationality, ethnicity, gender, class, are seen as just existing on an equal par with one another. We might like to think, Blommaert says, that all languages, cultures, all groups, in fact all people are equal, but in reality they are not. And it makes no sense to talk about cultural differences as if they are all equivalent. Vertical models of differences which look at power differentials, he argues, are more in line with reality. An approach to ICC which has the potential to take account of the relevance of power differences in roles and status is that of ethnography.

\section{Ethnographic Approaches to Communication}

To illustrate this particular model of intercultural communication, Blommaert refers to work by Gumperz and Hymes. The importance of this model, he says, is 1) that it recognizes the complexity of the relationship between culture and communication, and that 2) differences in communication in this model are not marked by national culture, but, critically, by differences in the context in which communications take place. Nationality is only one of the factors in that context of situation. Gumperz' contribution to the study of intercultural communication, Blommaert says, is on the one hand that he highlights that it is not so much 'culture' in the sense of values and norms which has an effect on communication, but instead 'communicative repertoires', such as conventions, 
speech styles and narrative patterns. These repertoires are formed by 'traditions' such as those of class and ethnicity which have become part of the language; 'we don't just use 'a' national language, like Dutch or German, but instead we always use a variety of 'a' language; 'a genre, a speech style, a type of interaction'. People identify themselves on the basis of such speech styles, which often relate to social traditions of class, gender, ethnicity etc. An important aspect of this is that these traditions and identities cannot be separated from issues of power. It makes a huge difference, Blommaert indicates, who the dominant party is in a particular interaction, whether, for instance, the interlocutor is the immigration officer or the asylum seeker for instance.

The all important role of a wider context means we cannot predict what will happen in an intercultural exchange purely based on someone's 'culture', whether national or otherwise, as the horizontal difference view holds. There are too many factors in different contexts at play. Moreover, we cannot predict what will happen in such an exchange; people might mutually adapt to one another's speech styles, both or either participant may sacrifice or exaggerate cultural conventions. In fact, more often than not, Blommaert says, 'ethnically' or 'culturally' marked aspects of communication are influenced by emotional factors such as feelings of frustration, anger or powerlessness. In other words, there is no fixed link between certain speech conventions and certain cultural groups; the reality of communication is too complex.

Paradoxically, the model of ethnography of communication was the main inspiration for communicative language teaching, but it was interpreted in a reductive manner, as I discussed in previous chapters, so that the principles of this model, which Blommaert describes as allowing for nuanced analyses of communicative events, were almost completely lost.

Incidentally, even though Gumperz carried out important work in this context by showing that a range of social factors influence communicative styles, including the power difference between interlocutors, when Gumperz applied his work pedagogically in a training context in 'Crosstalk' (1979), he largely ignored the notion of power. In Crosstalk Gumperz does exactly what Blommaert criticizes; he makes the trainees aware of the direct link between particular cultures and particular speech conventions. This highlights the issue of the training context, where pedagogy is more neatly organised and focuses on a limited, clearly defined area, where there generally is no room for reflection and complexity.

Whilst Gumperz, as Blommaert said, noted the role of power between participants in a communicative exchange, Hymes (1996) showed another aspect of power in intercultural relations; language varieties themselves are not neutrally valued, as some of these varieties are seen to be 'better' than others. Particular language varieties or even languages tend to be associated with certain attributes, particularly status, which immediately imposes a power structure on the interaction. But, apart from different hierarchical relations, what is important in relation to intercultural communication, is that power legitimises certain 
views over others, it legitimises certain languages and certain language varieties over others. And as language or language variety tend to be associated with a particular social group, the question becomes as Blommaert states, 'whose culture is being used in intercultural communication?', which we could paraphrase as 'whose version of reality counts'? The differences which occur between participants from different cultural backgrounds are not neutral. The many intercultural communication courses in a business context convey a very specific global form of intercultural communication where the language of interaction is almost always English and the participants are generally highly educated. But where intercultural communication involves a meeting of people who are members of different social groups such as in immigration contexts, these meetings take place in contexts where one interlocutor has more status and power than the other. Another factor then is the larger context of interethnic relations in that area or at that historical point of time and, I would suggest, the discourses which are in operation around otherness which would inform the assumptions and stereotypes which are held. When these discourses become dominant, such as 'the Clash of Civilisations' (Huntington, 1998), they become powerful as supposed 'truths'.

What is relevant to the foreign language teacher in this work is the notion that in intercultural communication we do not just deal with a national language, but that if we want to prepare our students for real intercultural exchanges we must make our students aware of language varieties, discourses, register, genre which, as Bakhtin showed, reference socially charged contexts. Or to use Risager's terms (2007), we should not just think about language and culture at the differential, but also at the generic level. And as Blommaert shows, it is not just being aware of the existence of these varieties, but also the value or status which they are afforded in certain contexts and in relation to other language varieties or genres. But intercultural communication is still more complex than that and, as Blommaert points out, 'difference is not always there, can appear in one context one time and not another time, and is also 'caught in patterns of social evaluation' (1998: 11).

\section{Crossing Ethno-linguistic Boundaries}

The third view that Blommaert identifies in the study of intercultural communication allows for difference and complexity in a much greater sense. Intercultural communication cannot be seen without taking account of the social dynamics amongst people within communicative events. Blommaert uses Rampton's (1995) study as the prime example of this view and argues that this could be a way forward to studying examples of intercultural communication. Rampton showed how young adolescents in urban areas in Britain did not stick to clear ethnic boundaries when using language associated with a particular ethnic descent. Instead they performed regular 'language crossing', switching 
in and out of ethnically marked varieties of English when communicating with friends from different ethnic groups or in different social settings. Ethnic identities were being manipulated and negotiated; the study showed 'how identities can be picked up, dropped, altered, combined and so on, in ways that defeat any form of simplism or singularity'. Rampton also concluded that the different speech varieties were not associated with one specific context of use, but were sometimes used for even conflicting purposes, whether as a sign of resistance, an expression of solidarity, or showing a recognition of prestige. Culture for these adolescents then, Blommaert says, serves as a set of resources which partly operates automatically, but can also be strategically activated in different circumstances and for different purposes.

This view of intercultural communication which Blommaert suggests here as a step forward in thinking about interculturality, is a marked change from the 'difference' view; not only does it not primarily focus on a national culture, it also emphasises that people move in and out of various forms of cultural symbolic behaviour, in terms of using different language varieties or genres, and indeed by feeling different allegiances. Moreover, it also shows that the same behaviour or language can be utilised for completely different purposes. The idea of context is made much more complex precisely because it allows for the use of conflicting discourses and indeterminacies.

There is a parallel in the boundary crossing model with thinking about identity and cultural complexity. Our sense of 'belongings' is formed by the affiliations to the various roles, relationships and memberships of 'communities of practice' people feel they are part of, as Kumaravadivelu (2008) says. None of these communities are fixed and stable entities in themselves. Instead they are complex mixtures of 'pleasure and pain', of 'trust and suspicion', of 'friendship and hatred' as Kumaravadivelu says, quoting Wenger. How these complexities of the different realities can overlap, was illustrated by Baumann in an ethnographic study of Southall, a very diverse and multicultural area in London. 'The vast majority of all adult Southallians saw themselves as members of several communities', each shifting and potentially conflicting with one another. 'The same person could speak and act as a member of the Muslim community in one context, in another take sides against other Muslims as a member of a Pakistani community, and in a third count himself part of the Punjabi community that excluded other Muslims, but included Hindus, Sikhs and even Christians' (Baumann, 1996).

\section{Significance of the Boundary Crossing Model for Language Teaching}

The strength of Blommaert's model, or view on intercultural communication, is that it acknowledges that context is complex and there is not a straightforward link between one particular context, especially not a national one, and par- 
ticular speech styles. The model is a useful way of thinking about intercultural communication in the context of language teaching. Even though I will not use the concept of code switching in a linguistic sense for this study, the idea of culture as a set of resources (linguistic and otherwise) that people can pick and choose from to utilise, resist and create new meanings, I think is very relevant for critical intercultural communication in language teaching. Blommaert's model does not give us the answers we need in terms of pedagogy and whether we should opt for a context or text-based approach, or what to include in a language teaching syllabus. Moreover, Blommaert seems to refer specifically to speech. We cannot, in short, apply his views directly to language teaching, but his models provide a way of thinking about intercultural communication which is important for us as teachers. His view of culture as 'resources' to draw upon bears similarities with Holliday's view (2004: 12).

The fact that choosing from these resources operates, not just on an unconscious, but also on a strategic level, is an important point. If people use these resources partly strategically on an everyday basis, they become more easily available for conscious reflection, which can be used in the language class.

The notion of switching and mixing language styles and varieties depending on a range of complex factors with regard to the social context, as well as factors outside the social arena such as emotions, can be made central to language and culture pedagogy. Such a pedagogy would focus on difference in terms of styles and discourses and look at the embedded ideologies and values, see context as influenced by a complex set of factors, focus on making learners take account of who they address and direct their communications specifically to their audience. This addressivity - 'the quality of turning to someone', as Bakhtin (1996 (1986): 99) so aptly calls it, comes into play particularly in writing, as students have more time for reflection on their language output. But an awareness of varieties of styles and discourses, and indeed how the reader is addressed, also helps students to delve deeper into text and go beyond the content of the text.

Cultural meanings are then created through discourses; structures of meaning which also hold in Bakhtin's words a 'stylistic aura' which reflect the ideology pertaining to that discourse. But these cultural meanings are often global. Areas of human activity are after all not limited to a particular national culture. For the language teacher who frequently is expected to teach the national paradigm, this provides a dilemma.

\section{Dilemmas of Intercultural Communication in the Language Classroom}

One of the dilemmas of intercultural communication for the language teacher is that on the one hand we want to emphasise the complexity and diversity of cultural environments that we are looking at in the classroom, and at the same time we cannot deny that certain tendencies and cultural patterns exist. Con- 
ceptualising culture within a pluriform society, with different sets of values, lifestyles, genders, political views and so on, can also easily fall prey to a similar essentialising of, what Holliday calls, 'small cultures' (2004: 63); describing such subcultures as consisting of people sharing a set of collective characteristics. This could still lead to learners thinking of culture or subculture as a fixed and bounded entity. It would be futile to think there are no differences between the way people live or make sense of their world, whether between different countries or groups within a country. But the most important thing is to recognise these patterns as tendencies which may be hard to pin down; with vague and fluid boundaries. As Blommaert said: the world is indeed full of differences, but these differences are not always there, or are not always the same, and they are partly determined by unequal power relations (1998: 11).

As I set out in the previous chapter, foreign language teaching has had a take on culture (and on language) using somewhat stereotypical and stable notions of a national culture. This is understandable to a degree, because, despite the fact we have all become part of a 'larger global tribe' (Appiah, 2006), national, and indeed sub-national realities, even as 'imagined communities' (Anderson, 1983), remain important in how people describe their complex cultural identities and subjectivities, as Holliday (2011) showed. In his study on this topic, he noted that nation is an 'undeniable powerful source of identity, security and belonging, but it is an external one which may be in conflict with more personal cultural realities. We can also see this in books which take a comical look at a national culture and focus on stable notions of a culture, e.g 'The Undutchables' (White and Boucke, 2006). These books are so popular and seductive precisely because the information they contain is so easily recognisable; we tend to recognise what we already know as it slots so easily into our existing mental schema. Coleman (1996) pointed out that students of German who spent time in Germany as part of their Residence Abroad scheme came back with all their ideas and stereotypes of Germany and the Germans confirmed.

In a recent survey of Dutch language teachers at Institutions for Higher Education worldwide, it was found that many teachers recognised the dilemma of not wanting to stereotype, yet felt that cultural information as part of language teaching is frequently about behaviour as part of a national culture. Teachers opted for giving cultural information accompanied with the warning: this is a generalisation, but nevertheless there is a core of truth in it (Rossum and Vismans, 2006).

I would like to suggest that the 'kernal of truth' view can be just as limiting as the stereotypical view, as it pretends to recognise complexity, but still focuses on essential meanings. We need knowledge about another culture, but that knowledge must be looked at critically and must be placed in context. The kernal of truth view is dangerous because it perpetuates the idea of fixed cultures.

I will now turn to the implications for the classroom. 


\section{Towards a New Conceptualisation of Interculturality in the Language Classroom}

A more useful way of conceiving of interculturality in the classroom, which allows for complexity, a level of fluidity, individual agency is the notion of being intercultural, put forward by Phipps and Gonzalez (2004), where 'being' is emphasised over 'knowledge.' They argue that the central activity of modern languages degrees should be 'languaging', 'being intercultural', and 'living with supercomplexity' ( $\mathrm{p} 8$ ). The key element in the process of being intercultural is that of 'languaging.' In 'languaging' the emphasis is on 'real' communication and dialogue in the classroom rather than on artificial language tasks; it is 'living in and through the language' (p.111). 'Being intercultural' means understanding another world, which takes place through the process of dialoguing with others and being part of another cultural group. Crucially, this process can only take place from a position where students challenge their world and 'let it be enriched by others' ( $\mathrm{p}$. 27). The notion of 'intercultural being', as conceptualised by Phipps and Gonzalez, focuses on engaging with the other, on processes and on critical reflection. Being intercultural is more than an attitude of how you feel towards other countries as Byram's notion of ICC holds. 'It is more profoundly about how one lives with and responds to difference and diversity. [....] It is about living out the network of diverse human relationships - not just abroad, but down the road as well' (p.115).

'Being intercultural' is not about getting information about the other culture, but it is about engaging with it, both from 'within' to get a sense of what the other thinks, feels and does, and from a position of real critical understanding. Phipps and Gonzalez argue for not just the insertion of critical reflection as part of the language curriculum (p. 92), but the active engagement which they call 'critical being. Learning is about 'testing and exploring ideas in and against reality, and then reflecting upon the process' (p. 124). This combination of the experiential and intellectual is found in the practice of ethnography as a way of understanding the cultural and social practices of a (cultural) group. But, Phipps and Gonzalez argue, ethnography is more than a tool to enable learners to develop into intercultural beings. It is about 'people meeting in human encounters and in ways which may change the way they see the world' (p.125).

I interpret the notion of 'being intercultural' as taking the learner conceptually out of the classroom, and into the real world. It is an intellectual engagement with the real world. It may consist of 'real' dialogues with fellow students, or even other speakers of the language, but the notion can also be extended to engaging with written texts as if in 'dialogue'; relating what is read explicitly to one's own experiences and understandings and to keep on querying these. Indeed in chapter $5 \mathrm{I}$ explore how students, when testing their ideas against their experienced 'realities', made them realise the positioning of the text we discussed. 


\section{Ethnography as a Method of Being Intercultural}

Ethnography for language learners, even though it hasn't yet made its way into many syllabi at university language departments, has nevertheless attracted increasing interest in the last few years as an exciting way to combine the intellectual and experiential aspects of engaging with the other culture. The aim of ethnography is twofold: on the one hand it encourages the learner to recognise the cultural in his/her everyday life and ideas by 'making the familiar strange. On the other hand the learner is encouraged to try and understand the 'strange' from within its own perspective. The learner will then start to recognise that what previously seemed natural, was actually culturally constructed. Of course, it is impossible ever to see things from the perspective of the other. We will always see the world through the filter of our own experiences. An important aspect of ethnography is to realise that what you see and observe, is coloured through your own experiences, your own cultural and social background, and ideas and assumptions, your own ethnocentricity. But, even with that knowledge, we can never truly know what phenomena, ideas, objects, customs, behaviour, everyday life events actually 'mean' for the 'other'. We cannot observe neutrally. Every observation will always have what Hermans (2007: 147) calls a 'blind spot', because every observation can be interpreted only from the context of those that do the observation.

The main technique of ethnography is creating 'thick descriptions': by giving extremely detailed accounts of what can be observed, students discover things which might otherwise have escaped their attention or would have been taken for granted. But thick descriptions involve reflection on one's own observation and response to what is observed at the same time. Doing ethnography then is to question the sources of evidence presented and thereby challenge assumptions and stereotypes (Barro et.al., 1998: 76-97).

Probably the first ethnographic project of its kind for language learners was the Ealing Project, in which students first made the familiar strange through writing 'home ethnographies' before applying this to a closely observed ethnographic project during their year abroad (Roberts, et.al., 2001). This project, though undertaken by language learners in the context of their modern languages degree and as preparation for their residency abroad, is not an actual language class, but more a cultural studies class.

Because its focus is on 'lived experience' and 'culture as practice' ethnography is very suitable for study abroad. Indeed, I adopted and adapted the Ealing Project in a similar way and incorporated it in a cultural studies course, which prepares student for doing their ethnographic year abroad project. But, ethnographic projects have also been used in the language classroom itself. Morgan and Cain (2000), for example, undertook a collaborative project between two schools; a French class at a school in England and an English class at a school in France. The aim of the project was to let pupils think about their own culture as 
well as that of the other group, seen from the 'other's' perspective. To this aim pupils were asked to represent aspects of their 'own culture' around the theme of 'Law and Order'. Students from each class worked in small groups to create cultural material for the partner class. In doing so they had to be aware of what was specifically English or French about the topic, but more importantly, they had to think about the communicative needs of the partner class, both in content and language use. By looking at the material the partner class produced, pupils could discuss and compare the similarities and differences. Whilst it may be said that this approach still did not encourage a non-essentialist attitude to the other culture, and was still located within a national paradigm, pupils were encouraged to think about the perspective of the other; to imagine how others might feel and how they might engage with information given to them.

Phipps and Gonzalez take integrating ethnography in the classroom probably furthest. One of the projects that Phipps worked on with her students was a project about 'rubbish' (Phipps and Gonzalez, 2004: 126). Students collected data and interviewed Germans living in Glasgow about environmentalism. This integrated project work outside, in the 'real world', with language work inside the classroom. This is an exciting initiative which includes project work as part of classroom work and makes a direct, experiential link between everyday experienced culture. Moreover, by interviewing Germans living in Scotland, a narrow national focus is avoided. I feel that projects such as these point the way forward to more ethnographic real world experiences, and should be explored further in language teaching. However, in my own pedagogy I adopted not a project approach, but I aimed to include ethnography as part of the general pedagogic activities in the classroom. This became a text-based approach using principles of ethnography. I will set this out below.

\section{Text Ethnography}

Ethnography is well suited to an intercultural approach to language teaching because of the opportunities it affords for being reflexive about one's own cultural environments and the focus on querying the 'taken for granted', as well as 'stepping into the shoes of others', although care needs to be taken not to see these cultural environments as fixed. But ethnography can be integrated further in the language classroom, I believe, than by just being the focus of separate projects, as in the Morgan and Cain study. Ethnography could also be usefully applied to looking at texts, thereby integrating text and context. Texts are after all a natural focus for the language and culture classroom. Moreover language always happens as text (Kress, 1985), and texts reflect and reconstruct specific instances of culture.

An ethnographic approach to text helps students to recognise how culture underpins texts, to query the taken-for-granted and to see how language and culture interrelate. This is a process of discursive mapping. However, an eth- 
nographic approach also looks at the role students have to play in their interpretation. Looking in an ethnographic way at texts then, allows us to make the 'familiar strange', and the strange familiar. Being intercultural through text then can be a pedagogy of an integrated look at language and culture which takes account of the complexity of context, interculturality and criticality. But, before we can discuss what it means to be intercultural through texts, we first need to look at what we mean by 'text', which I will do below. These views of text are similar, but not the same, as the views of language which I discussed in the previous chapter: views of the liberal humanist perspective; of a structuralist perspective; and text as a semiotic encounter where text and reader 'meet' to create meaning.

\section{Texts}

\section{Ways That Text Has Been Conceptualised}

For the purposes of this study, I am looking at texts as 'written' texts. Whereas my pedagogy sees text in a wider range as 'transmitters of meaning' which could also be visual and/or aural texts, I focus particularly on written text in the empirical part of this study. During the lessons which form the empirical part of this study (see chapter 5), I tried to alert the class, when discussing a particular text, to the extra layer of meaning added by the illustrations and page layout. However, this discussion did not generate illuminating data, and I do not include the multimodality of text in my discussion below.

Historically, the concept of text has been conceived in different ways within language teaching. I will briefly set out traditional views of text, before focusing on the conceptualisation of text which is the core of my pedagogy, i.e. that of 'cultuurtekst'.

In the liberal humanist educational tradition, which I discussed in chapter 1, text itself was not an issue for theorizing. Text is a written product, and not a process of communication. A product, moreover, which was the result of intellectual thought and ideas. The most important attribute of a text is the content which, in 'a good text' is generated through solid thinking and expressed in good writing. The quality of these thoughts is reflected in the actual quality of the language, the structure of the text and the strength of the argumentation. As the $19^{\text {th }}$ century educationalist Blair, cited by Emig, said, the aim was for writers to produce products of moral superiority and rationality: 'embarrassed, obscure and feeble sentences are generally, if not always, the result of embarrassed, obscure and feeble thought' (Emig, 1983: 7).

Texts in this traditional view are wholly the responsibility of the individual writer, regardless of whether anyone else, such as an editor could have had a role to play in the writing. The writer is thus unproblematised. The reader on the other hand has no role to play in the interpretation of the text, except, per- 
haps, to appreciate (and imitate in the case of learning to write) the quality of the text. The assumption then is that quality is not subjective, but objective, there is an agreed notion of 'the good text'. Moreover, it is a product which contains a stable meaning.

This view of text is now generally no longer held in the academic world, but it survives as a 'common sense' assumption amongst many people, as evidenced by newspaper discussions bemoaning the declining quality of writing of school pupils in the subject of English. As a result the notion of a 'good text' has an enduring appeal with (some) students, as I found out when analysing my data (see chapter 6).

The second view of text which I discuss here, is the structuralist view of text. This view, whilst less concerned with the idea of 'the good text', does also emphasise the autonomy of the text. But in contrast with a liberal humanist educational view, the emphasis shifts towards a more prominent role for the reader in 'extracting' meaning from texts (Wallace, 2003: 15). This view correlates with the view of communication put forward by de Saussure, the 'speechcircuit', which as Daniel Chandler says (2002: 176) can be seen as an early form of the transmission model of communication; the Shannon-Weaver model (1949). The latter sees communication as sending a message from person A (the sender) to person B (the addressee) as if it were a package. I would suggest that, again, this is the common sense idea of communication that most people, including our students would hold. This idea of communication as 'sending a message' is subsumed in much of (Dutch) language teaching practice, both in reading and writing tasks. Reading in foreign language classes then frequently consists mainly of comprehension tasks and activities, which typically include multiple choice tasks, or comprehension questions regarding writer intention or the meaning contained in the text as if these were unproblematic constructs.

Later versions of the structuralist model allow for a more complex idea of communication and crucially include the notion of context. This model also allows for a view of text beyond the written product alone. The text can thus be anything that 'sends a message', whether a conversation, a visual image or even a form of behaviour of dress. As such this model allows not only for a much broader view of text, but also the emphasis in communication has shifted from the producer of text to the text itself.

A more interactional version of the structuralist encoding and decoding view of communication, is that espoused by Widdowson (and others) in relation to language teaching, which grants a greater role to the reader and to the role of context than the traditional views based on the Shannon-Weaver model. For Widdowson reading is not just a matter of transferring information from the author to the reader, but is instead a process of communication; the reader is active in the decoding process, engaging his or her prior knowledge, experiences and ideas. Encoding, or writing, is not just a formulation of messages, says Widdowson (1979: 175), but also giving pointers to the reader to help him or her along in the process of decoding. The responsibility of the text still lies 
with the writer in the sense that he needs to take account of the reader in writing a text. A writer must therefore see writing as a cooperative activity. The writer provides directions to the reader and anticipates the questions an imaginary and critical reader might ask; questions such as: Oh yes? How do you know? In that sense Widdowson's view of text may also seem to be reminiscent of the liberal view of 'the good text', because the text needs to adhere to certain criteria. But these criteria are not necessarily located in the clarity of thought of the writer, but in the way the writer directs him/herself to the audience.

This is the same addressivity that Kramsch emphasises in her approach, where she borrows the term from Bakhtin. However, Kramsch (and Bakhtin) see this reader-oriented writing as a social aspect; the writer imagines the reader and what his/her previous knowledge, interests, objections to the text and so on, can be. Widdowson's structuralist position towards writing, on the other hand, is not dissimilar, I would suggest, from the maxims that guide the conversational Cooperative Principle put forward by Grice - communication is understood as being guided by the 'rules' of 'being truthful', 'being clear', 'being informative', (i.e. not being too wordy for the purpose) and 'being relevant'.

Widdowson's view allows for a stronger role for the reader than either liberal or structural views generally take on board, as the writer relies on the active participation of the reader in order to comprehend the text by understanding the pointers the writer gives, but it also sees communication more as something taking place between individuals, rather than as a social process.

The third view of texts which takes the interactional element much further still is that explicated by Halliday, who sees texts as both product and process. The text is a product in the sense that it is an artefact, it is there in the physical sense and we can read it. But at the same time, text is also an interactive process, 'a semiotic encounter' where participants (the writer and reader) meet to create meaning in a particular situational context. Wallace uses Halliday's conceptual framework of text as a starting point in her critical pedagogy of reading where she sees reading and writing as closely interrelated (2003: 12). Wallace locates her work in CLA (Critical Language Awareness), which as I discussed in chapter 2, as a pedagogy encourages learners to deconstruct texts to critique the ideology embedded in them; analyzing linguistic features in the text raises students' awareness of how the discourses privilege those with power. Wallace takes a view of reading where text interpretation is partly guided through analyzing the social interaction between the participants, the social situation and the language used. This is not a completely fluid and open interpretation of the text where it is up to the individual reader to recreate his or her meaning. Following Eco she says that texts do carry meaning in and for themselves 'apart from writer intention (and indeed apart from reader interpretation) at a number of levels signaled, in complex ways, by the nature and combining of the formal features selected' (ibid. p.13).

My own view is to some degree in line with Wallace, in the sense that in text interpretation, at least in the context of language education, we can look 
for 'preferred readings' (ibid. p. 16) which students can access by considering specific linguistic features and contexts. These apparent intended meanings of a text, refer to, as O'Regan (2006: 113) says, how, 'from the perspective of a reader, the text seems to want to be read'. Preferred readings then are the apparent arguments, perspectives and orientations, as they appear to the reader, and, O'Regan states, 'it is the text itself [that] seems to indicate this preference' (ibid.). But, in my own pedagogy, and indeed the framework for analyses of texts, which I used with my students, I also deviate from Wallace, in the sense that, when looking at texts, my concern is not so much with ideology, but rather with discourses as meaning making practices and how these produce knowledge and make claims to truth. Looking at discursive formations in texts also gives the student reader a window on the context in which these texts are produced. And even though I assume that text interpretation does not allow unlimited readings, as I argued earlier, I also take into account that students rewrite the text; they imbue it with their own meaning, derived from their experiences and discourses to which they have been exposed, and the intertextual knowledge they gained through these.

I have argued earlier that in my own pedagogy I encourage students to employ various critical strategies to interpret texts by referring to the linguistic choices made. I am partly borrowing from Wallace (2003) in this. But, as my concern in the foreign language classroom is not only with critique of how power is sustained and constructed in texts, but also with culture, I am using a different view of text which allows for both elements. For this reason, I am focusing on models of text which are more suited to 'being intercultural' through text.

Bakhtin offers a good starting point.

\section{Being Intercultural Through Texts: Dialogism and Addressivity}

Text, or utterance, according to Bakhtin, is about a dialogue with an other. Text then, does not exist in its own context, but is always directed to someone else, and as such his model of text can function also as a model of communication. Text can therefore be seen not just as a product in its own right, but it is always produced for someone else: a reader, interpreter, listener, which makes it relevant for intercultural learning, both in reading and writing.

This 'addressivity' goes further than just helping the reader or listener along through using structural markers in the text or writing in a reader-friendly manner, such as writing with the use of discourse questions in mind, as I discussed above in relation to Widdowson's view of texts. Instead, Bakhtin's notion of addressivity or 'dialogism' means taking account of the reader or listener in a more substantial way and considering what the possible reader or listener's previous knowledge and expectations and possible responses to the text might be. A reader's responses to a text are based on his/her cultural and social experi- 
ence and history, particularly in relation to previous reading experiences, but also in relation to the addressee's conceptual world, which is made up partly of conventions of communication in certain areas of life (e.g. genres such as academic articles, law reports etc.), as well as his or her own ideological positions, or at least the discursive fields the addressee is familiar with.

But text and communication are not just addressed towards a (future) reader who has a past and cultural baggage; texts (utterances) are also addressed to past language or communication. Language, Bakhtin says, is always a response to a greater or lesser extent to other utterances (1996 (1986): 91, 92). This applies to communication in real time, e.g. a response to a previous utterance in a conversation, or a text which has been written in response to another text or any other intertextual references.

If we apply this notion of engaging with the other to 'being intercultural', the intercultural learner is not just responding or engaging with the other culture, but also with another past. Words, like texts, are not neutral. There may be neutral dictionary meanings of words which ensure that speakers of a given language understand one another, Bakhtin says, but in live speech communication words are always contextual (1996 (1986): 88). Language in use is not neutral because the context of the whole utterance gives the word 'colour' or 'sense.' Furthermore, as speakers we are not the first people to use words. What we say is not just addressed to the object, the topic we speak about, but to what others have said about it. A text is a 'link in the chain of speech communication' (ibid. p. 94) and it cannot be seen separate from this chain. A text, or an utterance, carries echoes with the past, or as the playwright Dennis Potter says it more succinctly: the problem with words is that you don't know whose mouths they have been in (quoted by Maybin, 2001: 68).

This is of particular relevance to the foreign language learner, who has not been socialised in the foreign language discourse communities and indeed might not be able to relate any discourses to particular people, events or cultural and ideological views, at least not in the foreign language context. To understand a text, you can never only take the thematic content into account, because the text also responds to what others have said about the same topic. A text is then not just about its content, but it is a representation of something in relation to the other texts to whom it (perhaps unwittingly) refers: texts are filled with 'dialogic overtones' (Bakhtin, ibid., p. 92).

But texts do not just exist as 'echoes of the past', texts themselves are not just written within one voice or discourse. As Kress showed, frequently there are various, even conflicting, discourses in a text, and it is these clashing discourses which give rise to the text itself (1985: 82). This heteroglossia consists of the seemingly endless voices and discourses in which social and ideological positions are embedded.

It is the notion of dialogism - being in dialogue with past, present, future and the other, which, I believe, constitutes the inter in intercultural. The inter 
in this interpretation is not a direct relationship between two cultures. As I argued earlier, intercultural relations are a complex set of cross cutting allegiances in which speakers act their complex multifaceted identities, or different 'belongings'. In the next section I explain what the cultural in intercultural is when we adopt a Bakhtinian version of texts, as a way of communicating with the other.

\section{Cultuurtekst as Discourse and Representation}

In the previous chapter I already pointed to the notion of 'cultuurtekst', text as culture, coined by Maaike Meijer, a Dutch feminist literary theorist. She developed this notion of text into a theory of text interpretation or reading, mainly for literary analysis purposes. She focuses particularly (following Kristeva, 1966) on the notion of intertextuality contained in Bakhtin's view of language being 'echoes of the past', but, in literary analysis, she maintains, recognising intertextuality is a limitless task. Often it cannot even be determined exactly how or where a text is borrowing from other texts. In order to create a framework for literary interpretations outside the notion of literary intertextuality, it makes more sense, she suggests, to recognise the discourses (in a Foucauldian sense) in a text. Texts are not created as fresh and new meanings, but are a reworking of old notions and ideas and conventionalised historically accepted ways of talking about certain things. This 'culturally routinised way of talking', Meijer calls 'cultuurtekst'.

Culture then, in 'cultuurtekst' is the 'conglomerate of accepted and recurrent motifs and ways of representation around a theme, which is organising itself again and again in new texts, whether literary, journalistic scientific or otherwise' (my translation) (Meijer, 1996: 33). It is meaning-making in relation to the whole cultural space; 'the scenarios' which are provided by the surrounding culture. Each individual text is a retake of those scenarios, she says. 'Cultuurtekst' encourages us to look at how a text rewrites and reproduces the available scenario. Or, in other words, how a text re-articulates the commonly accepted meanings, values and attitudes.

Meijer's view of 'cultuurtekst' is not a completely open-ended framework. It is not about a text having a single meaning, but about not having infinite meanings either. Groups of readers who have been socialised in similar ways, will 'smell', as Meijer calls it, similar discourses. They recognise the underpinning ideologies and values without being able to quite 'put their finger on it', as students have explained this sense of vague recognition to me.

Meijer's notion of 'cultuurtekst' is close to Foucault's notion of discourse, but it differs from it in that her notion encompasses both that of the individual concrete text itself, as well as that of the 'invisible' or implicit discursive fields which are operating within those texts. (1996: 33-35). This notion is useful for 
language teaching, as we are not just dealing with discourses, but also with text itself at a 'textual level'.

\section{Mapping Discourses}

Using the notion of 'cultuurtekst' also gives us the advantage of seeing culture in more pluriform terms: not a formulation of features specific to a national culture, but as a mapping and critiquing of discourses. I derived at the term 'discursive mapping' from Pennycook (2001), and see it, as he does, as a 'problematisation' of texts. I conceptualised discursive mapping as part of discussing with students how meanings in the text are created through discourses. This allows us, as Pennycook says, to map out different formations of meaning and to see how these are constructed through intertextual relations: a search for how social reality itself is produced and reproduced in language (ibid: 111). In this, the discursive mapping approach is a critical undertaking. O'Regan (2006) developed a model for reading texts in the classroom, in which he uses the idea of discursive mapping, an approach which he calls TACO, the 'text as critical object'. His model incorporates a number of stages from looking at the 'preferred readings' of texts, 'how the text seems to want to be read' (ibid: 24), through to a 'representative', a 'social', and a 'deconstructive' interpretation. I did not use O'Regan's model for my own 'cultuurtekst' approach to reading texts in the classroom, since his study was not available then, but I will come back to the TACO approach again in the next chapter when I discuss my own framework for text analysis.

Seeing text as 'cultuurtekst' then also brings to the fore the multiple discourses, to which Kress refers (1985: 7) and which are current in any context. Bakhtin calls this 'polyphony' (multivoicedness). Any context, except the most stable one, contains a range of 'voices'. I take 'voice' here to be similar to discourse. Bakhtin refers to different ideologies and discursive forces being inherent in all words and forms: 'Each word tastes of the context and contexts in which it has lived its socially charged life: all words and forms are populated by intentions.' (1981: 293).

The idea of 'cultuurtekst' then gives us access to the idea of culture as a complex, fluid and dialogic construct, which whilst containing patterns of meaning and behaviour, also recognises that these patterns change and merge and submerge in (sometimes unpredictable) ways.

An added advantage of applying the model of 'cultuurtekst' to language teaching, is that it gives language classes more intellectual content, even if discussing trivial texts, i.e. texts with a popular appeal, or everyday topics. It helps learners to think about language at a more theoretical level, as well as touching on the notion of addressivity, and the processes of meaning making, which is an inherently critical task. 
Finally, the idea of 'cultuurtekst' works not only as a mode for interpreting texts, but, when combined with the notion of 'addressivity' is also very useful as an awareness tool for writing texts. I have incorporated this into the syllabus of my general language class (see chapter 4 for an overview). My emphasis in the fourth year language class under study was particularly, but not exclusively, on reading and writing, as an intellectual dialogue.

\section{Implications for Teaching}

The need to conceptualise text in social ways in terms of the context of production and reception is fairly widely accepted these days. However, as indicated before, in the practice of language teaching an uncomplicated view of text is still prevalent. Texts are frequently used as vehicles for grammar and vocabulary work, for translation, or for comprehension exercises on the content level only. Questions of text generally are aimed to 'check' whether the learner has passively understood the surface messages contained in the text. In language teaching, text is still frequently seen as a written product; a carefully constructed framework with a clearly demarcated beginning and end which constitutes an intelligible, cohesive piece of writing, and any language work relating to texts frequently separates the activities of reading and writing. Students also frequently hold similar assumptions about text. As I show in chapters 5 and 6 students can struggle to recognise the complexity of texts as a result of these assumptions.

Yet on the other hand, students also engage with texts as social and cultural beings themselves; their responses to texts are based on their own experiences, ideas and assumptions. This is what I turn to next.

\section{Personal Lived Experience}

Traditional psychological schema theory (cf. Bartlett, 1932) holds that readers relate the incoming data they receive from the text to existing mental representations of situations or events. These are, as Widdowson (1983: 34) points out, primarily cognitive constructs which aid the organisation of information.

However, information is always located within a social context (Wallace, 2003: 22). This is the context of reception, the context in which the information is received, which is located within the wider context of culture, i.e. the views, ideas, knowledges and discourses which the reader is surrounded with or has encountered.

The previous knowledges and experiences which readers use to interpret the text relate to areas of academic as well as social experience; what they have read, learnt or heard about the topic, whether in formal education or through the media or everyday life. Moreover, readers also relate the text they read to 
their 'lived experience' of their relationships and encounters with other people which include power relationships. In short, we interpret texts by relating them, frequently unconsciously, to the discourses we have been exposed to ourselves. These unconscious understandings take on a taken-for-granted assumption of the world.

The resonances people hear are relevant and indeed give meaning to the text, but interpretations are never complete. They are dependent on the frameworks people use, the situation they are in, their experiences and interests, their lifeworld knowledge (cf. Habermas, 1984). In short we see texts from our own ethnocentricity. We also have, as said before, our own 'blindspots'. In order to deal with these and to try and take a position 'outside' the text, readers need to be reflexive about their own position.

Asking students to 'map' the discourses in a text, as I do in my 'cultuurtekst' pedagogy, brings to the fore two things: firstly, you need to take a position outside its discourses in order to critique a text, otherwise the discourses will seem 'natural'. Discourses are, after all, resistant to internal criticism, as Gee has said (2009 (1990): 161). Conversely, students may not be familiar with the discursive fields that gave rise to the text, as they would not share the knowledge inherent to which the text implicitly refers, in which case it may also be hard for them to 'problematise' the text or they may be half conscious of the discursive fields, but cannot quite 'put their finger on it?. To access the cultural meanings through discourses on which the texts draws then, we can, I suggest take the position of an ethnographer; an ethnographer of text, which includes the notion of reflexivity. I will turn to this next.

\section{Being Intercultural Through Text: Reading as a Text Ethnographer}

An ethnographer looks at cultural difference from both an inside and an outside perspective. Taking an inside (emic) perspective is trying to see the world as the 'other' experiences it, i.e. 'trying to stand in the shoes of the other' through being as much part of the experience as possible, by talking to people and being a participant observer. Of course an ethnographer can never completely understand the inside perspective; it can only ever be an interpretation. At the same time ethnographers try and take an outside (etic) perspective by trying to be aware of their own assumptions which influence their interpretation of what they see. This is the outside perspective, 'making the familiar strange' through creating 'thick descriptions'.

I consider the text ethnographer to go through similar processes in reading a text. An inside perspective of text cannot be the same raw everyday experience of the ethnographic observation or interview. The text is itself already a mediated artefact of the social and cultural world. However, by reading a text from an inside perspective, the text ethnographer is not so much trying to under- 
stand the writer of the text, but the environment the writer is describing in real life. This means the reader tries to understand the content of the text in relation to the wider cultural environment to which the writer wittingly or unwittingly refers. But, importantly, the reader can only understand the content and context in relation to her own experiences. So trying to understand the text from an inside perspective, i.e. trying to understand what the text might mean for the audience for whom it is intended, the reader will have to make use of her own experiences. These experiences could be those of empathy with the ideas or participants in the text, or these experiences could be brought to bear in relating and exploring the ideas and descriptions in the text against the reader's own reality. This is an 'engaging with'. It is not quite the same as the 'languaging' concept from Phipps and Gonzalez, because it does not involve 'real' faceto-face engagement in the language, but taking an emic perspective as a text ethnographer, can, I believe, be an engagement with otherness and relating it to oneself. Even if it is not a 'raw' ethnography in its experiential form, it is an intellectual engagement through relating the text to one's own experience and ideas and making it 'real'. In the classes which I used for data collection, there were some almost 'raw' experiences as students emotions became part of the very personal responses to that text, as I will show in chapter 5 in relation to a particular instance.

But the inside perspective needs to be accompanied by an outside perspective, i.e. reflecting on the taken-for-granted interpretations the reader makes herself. By being reflexive about his or her own interpretation, the reader engages in a process which queries the taken for granted realities and interpretations which reflect his or her own assumptions which are part and parcel of his/her ethnocentricity.

Again, the outside perspective I am describing is not quite the same as an etic perspective, as it does not involve making 'thick descriptions', but it can be a way of 'making the familiar strange'.

\section{Summary and Conclusion}

This chapter set out more specifically the underpinning ideas of my pedagogy. I drew on Byram and on Kramsch's early work, and on Guilherme's critical pedagogy. I aligned myself with the latter's critical emphasis, with Byram's focus on 'the everyday' aspects of culture, and with Kramsch's notion of context as complex and multilayered, her focus on text and on the notion of dialogue in class. I interpret this dialogue as taking place between students themselves as well as in relation to the teacher and the text under discussion, including the multiple discourses which occupy the cultural spaces which exist and open up in such dialogues.

Whereas language and culture in language teaching has been frequently seen as relating to information about the target country, and what to say in what 
situation, intercultural communication as a discipline, developed initially for diplomacy and applied to business contexts, focuses exclusively on interpersonal relations, seeing a direct link between 'a' communicative style and 'a' culture. I argued, drawing on Blommaert, that language and culture teaching should not focus on this perceived link, because even though there are patterns of communication in specific, including national, groups, language teaching should take account of linguistic and cultural complexity.

One way of conceptualizing a new way of thinking about intercultural communication is that put forward by Phipps and Gonzalez of 'being intercultural'; an actual engagement with 'the other' in and through language. Ethnography is an excellent tool to encourage interculturality, as it encourages students to observe, participate in, engage with, and reflect about the 'other' in relation to themselves and their own complex cultural environment. Even though ethnography is about engaging with 'real' situations, I argue that the idea can be applied to looking at text as well.

I set out different views of text which have prevailed in education, but the view of text which allows for a critical, an ethnographic, and a dialogic reading is that of 'cultuurtekst', as this view of text combines the idea of text as a product, and text in relation to the context of culture as shifting, complex and reflecting multiple discourses. The idea of 'cultuurtekst' then underpins my pedagogy. The advantage of this model, I argued, is that it lends itself to 'discursive mapping, which I see as both a critical practice and as an engagement with the cultural contexts of the texts.

In the next chapter, I set out the context in which this study took place, discuss the text I used for this study and I will introduce the framework for analysis which I used with the students. 